\title{
Laser ablation of the prostate: a safe effective treatment of obstructive benign prostatic disease
}

\author{
Edward Woods, MD, FRCSC
}

Can Urol Assoc J 2010;4(5):344-346

ower urinary tract symptoms (LUTS) are common; $60 \%$ of men suffer from LUTS and its prevalence increases with age. ${ }^{1}$ Initially definitive treatment of benign prostatic obstruction was surgical. With continued development and improvements, transurethral resection of prostate (TURP) has become the gold standard.

In the 1980s, TURP was the second most common operation in the United States (among Medicare recipients) after cataract extraction. ${ }^{2}$

Since the 1980s, however, the development of medical treatment and other changes have decreased the number of surgical procedures for bladder outlet obstruction by over $40 \%{ }^{3}$ As well, the development of minimally invasive surgical therapies (MIST) has decreased the number of TURPs performed. Minimally invasive surgical therapies procedures include transurethral microwave treatment (TUMT), transurethral needle ablation and laser prostatectomy.

Laser prostatectomies were first developed in the early 1990s with visual laser ablation of the prostate (VLAP) by Costell $\mathrm{O}^{4}$ and Roth's transurethral laser induced prostatectomy (TULIP). ${ }^{5}$ These procedures, which used the YAG laser wave-length, had limitations based on prostate size issues and the coagulation effect of the $1024 \mathrm{~nm}$ YAG wave length, which caused significant rates of irritative side effects which sometimes lasted for long periods of time.

Further developments include interstitial laser coagulation of the prostate and holmium laser prostate enucleation and (HoLEP), holmium laser ablation of the prostate (HoLAP), which remain in use. Interstitial laser coagulation of the prostate has a somewhat variable effect. Holmium laser enucleation of the prostate, developed by Gilling and colleagues, provides excellent long-term results. ${ }^{6}$ Issues with HoLEP include its high learning curve and complications, such as capsular perforation and the need for morcelation. These issues have limited its popularity to some degree. Laser ablation of the prostate is the most relevant alternative to TURP amongst the laser techniques. Developed by Malek with the potassium-titanyl-phosphate (KTP)/lithium triborate (LBO) $532 \mathrm{~nm}$ wavelength,7 Greenlight laser ablation (AMS, Minnetonka, MN) has become the most common laser technique used in the United States (Fig. 1). The $532 \mathrm{~nm}$ wavelength is absorbed well by hemoglobin and poorly by water. The $533 \mathrm{~nm}$ KTP wavelength causes vaporization of prostate tissues with a 1 to $2 \mathrm{~mm}$ zone of coagulation necrosis. This results in a TURP-like defect with little or no bleeding. Holmium and thullium lasers have also been used to achieve laser ablation.

The most robust data have been accumulated with the KTP/LBO (potassium-titanyl-phosphate/lithium triborate) wavelength, which has demonstrated that laser ablation of the prostate is a worthwhile alternative to TURP. Significant advantages are seen with laser ablation with the $532 \mathrm{~nm}$ wavelength. Superior hemostasis, short learning curve for the surgeon, ability to look after the average patient as an outpatient, avoidance of TUR syndrome, transfusion, and avoidance of secondary declotting procedures are all advantages of the technology. The ability to operate on an anticoagulated patient is a definite advantage (Table 1). With more than a decade of experience with KTP/LBO laser ablation, we have accumulated long-term data showing stable durable results (Table 2$).{ }^{8}$ Direct comparison of TURP and KTP photoselective vaporization of the prostate (PVP) show equivalent results (Table 3). ${ }^{9-12}$ Moreover, the direct costs of PVP laser ablation is cheaper than MISTs and

1270

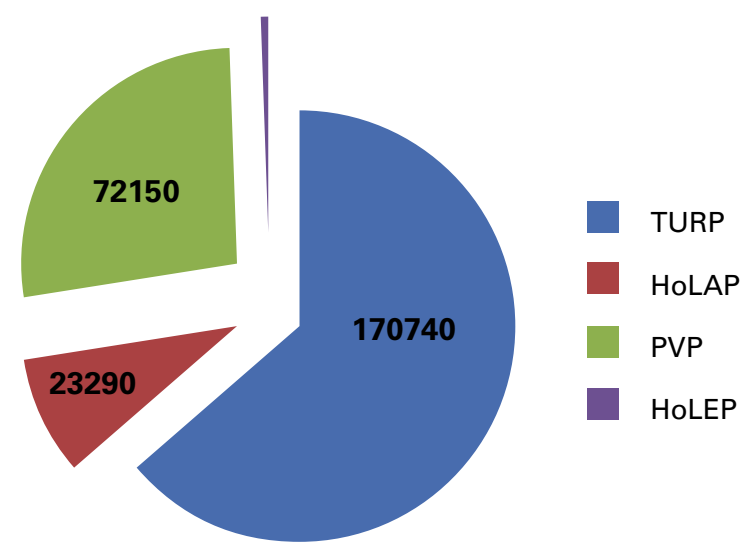

Fig. 1. Number of procedures (as determined by US Medicare), 2008. ${ }^{2}$ TURP = transurethral resection of the prostate; HoLAP = holmium laser ablation of the prostate; PVP = photoselective vaporisation of the prostate; HoLEP = holmium laser enucleation of the prostate. 


\begin{tabular}{|c|c|c|c|c|c|c|}
\hline & \multicolumn{6}{|c|}{ Time point } \\
\hline & $\begin{array}{l}\text { Baseline (SD) } \\
\quad(n=94)\end{array}$ & $\begin{array}{c}6 \text { months (SD) } \\
(\mathrm{n}=76)\end{array}$ & $\begin{array}{c}1 \text { year (SD) } \\
(\mathrm{n}=66)\end{array}$ & $\begin{array}{c}2 \text { years (SD) } \\
(n=48)\end{array}$ & $\begin{array}{c}3 \text { years (SD) } \\
(\mathrm{n}=32)\end{array}$ & $\begin{array}{c}5 \text { years (SD) } \\
(n=14)\end{array}$ \\
\hline AUA-SI & $22(6)$ & $4.6(2.3)$ & $3.8(2.4)$ & $3.7(2.2)$ & $3.4(1.7)$ & $2.6(1.6)$ \\
\hline Omax (mL/sec) & $7.8(2.3)$ & $26.4(9.5)$ & $27.1(10.6)$ & $26.6(11.3)$ & $23.6(9.2)$ & $22.2(9.0)$ \\
\hline PVR (mL) & $197(143)$ & 37 (34) & $43(52)$ & $18(28)$ & $23.6(28)$ & $25(26)$ \\
\hline
\end{tabular}

TURP ( $\$ 4291.00$ vs. $\$ 3368.00$ in Australia). ${ }^{13}$ There are also potential advantages for patients in terms of lower morbidity and earlier return to work. Its effectiveness appears to confer an advantage over other minimally invasive techniques. ${ }^{12}$ One problem with Greenlight laser procedures has been a frequency urgency syndrome which is seen in 5\% to $15 \%$ of patients. As surgeons pass their 20-case learning curve and become more adept at vaporizing with higher power output range of the laser (vaporation increases, coagulation and irritation decreases), this percentage will decline. Medical intervention with nonsteroidal anti-inflammatory drugs, phenazopyridine and anti-cholinergic agents may be used. Typically symptoms resolve in 6 weeks.

Any advantage of TURP in terms of ability to diagnose prostate cases on histologic analysis can be countered by following the predictable $30 \%$ drop in prostate-specific antigen with PVP. Transrectal biopsy is still possible after PVP and it is important that neoplasm be detected in patients after PVP. Neither TURP nor PVP are a primary diagnostic tool for prostate cancer.

New improvements in laser power and development in systems for the $532 \mathrm{~nm}$ wavelength will be helpful in improving the results from laser ablation. As well, bipolar resection and plasma resection may also have the ability to improve TURP's clinical outcome. Early experiences with bipolar resection have been challenging in terms of speed of resection and hemostasis, but this may improve with time. Ideally, a randomized trial would generate the best possible level; this would provide evidence to compare PVP laser prostatectomy and TURP. A study is ongoing of these modalities with McMaster University, Hamilton, Ontario, Canada and the PATH (Programs for Assessment of Technology in Health) program for the evaluation of new medical technologies. Large prostates continue to be a challenge both for regular TURP and laser ablation. Large glands can be looked after with the 120-watt laser system. A hybrid combination of vaporization and resection developed by Dr. R. R. Gonzalez allows laser resection of prostates over $100 \mathrm{cc}$ with safety (personal communication). A randomized trial of 120 patients with 3-year data using the 120-W HPS Greenlight laser compared to conventional TURP showed that PVP is clinically equivalent to TURP. This provides a boost to the evidence supporting PVP's clinical benefit. ${ }^{14}$ Current improvements in fibre durability and laser power will also allow the treatment of larger prostates. PVP laser may not only be an alternative to TURP, it may ultimately supplant it. Hopefully, the patient will ultimately be the winner. Until these data are published, we have sufficient evidence that PVP laser ablation generates equivalent results to TURP with improved side effect profiles and lower cost.

Urologist, The Scarborough Hospital, Scarborough, ON

Competing interests: None declared.

This paper has been peer-reviewed.

Table 2. Comparative clinical outcome with photoselective vaporisation of the prostate and transurethral resection of the prostate

\begin{tabular}{|c|c|c|c|c|c|c|c|c|c|}
\hline & \multicolumn{3}{|c|}{ IPSSa } & \multicolumn{3}{|c|}{ Omax (mL/sec)* } & \multicolumn{3}{|c|}{ PVR (mL)* } \\
\hline & Baseline & 6 months & $\begin{array}{c}\text { Percent } \\
\text { change from } \\
\text { baseline }\end{array}$ & Baseline & 6 months & $\begin{array}{c}\text { Percent } \\
\text { change from } \\
\text { baseline }\end{array}$ & Baseline & 6 months & $\begin{array}{c}\text { Percent } \\
\text { change from } \\
\text { baseline }\end{array}$ \\
\hline PVP (n=64) & $\begin{array}{l}18.1 \\
(5.9)\end{array}$ & $\begin{array}{c}5.2 \\
(2.1)\end{array}$ & $\begin{array}{c}71.3 \% \\
p<0.001\end{array}$ & $\begin{array}{c}6.9 \\
(1.9)\end{array}$ & $\begin{array}{c}18.1 \\
(10.3)\end{array}$ & $\begin{array}{l}162.3 \% \\
p=0.01\end{array}$ & $146.1(106.9)$ & $12.9(28.1)$ & $91.2 \%$ \\
\hline TURP ( $n=37)$ & $\begin{array}{l}17.3 \\
(6.3) \\
\end{array}$ & $\begin{array}{c}4.8 \\
(1.6)\end{array}$ & $\begin{array}{c}72.3 \% \\
p<0.001\end{array}$ & $\begin{array}{c}6.9 \\
(2.2)\end{array}$ & $\begin{array}{c}19.1 \\
(11.0)\end{array}$ & $\begin{array}{c}176.8 \% \\
\text { NS }\end{array}$ & $\begin{array}{l}120.7 \\
(49.0)\end{array}$ & $\begin{array}{l}14.4 \\
(8.3) \\
\end{array}$ & $\begin{array}{l}88.1 \% \\
\text { NS }\end{array}$ \\
\hline
\end{tabular}

A total of 86 patients were evaluable at 6 months. ${ }^{12}$ IPSS = International Prostate Symptom Score; Qmax = maximum flow rate; PVP = post-void residual urine; PVP = photoselective vaporization of the prostate; TURP = transurethral resection of the prostate. ${ }^{*}$ Comparison between treatment groups was not significant at 6 months for any parameter. 
Woods

Table 3. Comparison of transurethral resection and laser ablation of the prostate

\begin{tabular}{lcc} 
& KTP/LBO laser ablation of the prostate & TURP \\
\hline 1. Outpatient & Yes $>90 \%$ & No \\
\hline $\begin{array}{l}\text { 2. "TUR" syndrome (of hyponatremia, } \\
\text { confusion, seizures, glycine toxicity) }\end{array}$ & No & Up to $2 \%$ \\
\hline 3. Suitable for anticoagulated patients & Yes & No \\
\hline 4. Transfusion & Rare & $0.4>7.1 \%$ \\
\hline 5. Retrograde ejaculation & $25-50 \%$ & $50-75 \%$ \\
\hline 6. Secondary declotting procedure & No & $1.3 \%$ \\
\hline 7. Intraoperative bleeding & Rare & $0.4>21 \%$ \\
\hline 8. Learning curve & $15-20$ cases & 50 cases \\
\hline KTP $=$ potassium-titanyl-phosphate; LBO = lithium triborate. & & \\
Adapted from Wosnitzer et al. ${ }^{10}$ & &
\end{tabular}

\section{References}

1. Irwin DE, Milsom I, Hunskaar $S$, et al. Population-based survey of urinary incontinence, overactive bladder and other lower urinary tract symptoms in five countries: results of the EPIC study. Eur Urol 2006;50:1306-14.

2. Wei JT, Calhoun E, Jacobsen SJ. Urologic diseases in America Project: benign prostatic hyperplasia. J Urol 2005; 173:1256-61.

3. YuX, Elliot SP, Wilt TJ, et al. Practice patterns in benign prostatic hyperplasia surgical therapy: the dramatic Increase in minimally invasive technologies. J Urol 2008;180:241-5.

4. Costello AJ, Johnson DE, Bolton DM. Nd:YAG laser ablation of the prostate as treatment of the prostate as a treatment for benign prostate hypertrophy. Lasers Surg Med 1992;12:121-4.

5. Roth RA, Aretz HT. Transurethral ultrasound-guided laser-induced prostatic (TULIP procedure): a canine prostate feasibility study. J Urol 1991;146:1128-35.

6. Gilling PJ, Aho TF, Frampton CM, et al. Holmium laser enucleation of the prostate: results at 6 years. Eur Urol 2008:53:744-9.

7. Malek RS, Barrett DM, Kuntzman RS. High-power potassium-titanyl-phosphate (KTP/532) laser vaporization prostatectomy: 24 hours later. Urology 1998;51:254-6.

8. Malek RS, Kuntzman RS, Barrett DM. Photoselective potassium-ititanyl-phosphate laser vaporization of the benign obstructive prostate: observations on long-term outcomes. J Urol 2005;174(4P+1):1344-8.
9. Bachmann A, Scurch L, Ruszat R, et al. Photoselective vaporization (PVP) versus transurethral resection of the prostate (TURP): a prospective bi-centre study of perioperative morbidity and early functional outcome. Eur Urol 2005;48:965-71; discussion 972.

10. Wosnitzer MS, Rutman MP. KTP/LBO laser vaporization of the prostate. Urol Clin North Am 2009;36:47183 , vi.

11. Al-Ansari A, Younes N, Sampige VP, et al. Greenlight HPS 120-W laser vaporization versus transurethral resection of the prostate for treatment of benign prostatic hyperplasia: a randomized clinical trial with midterm follow-up. Eur Urol 2010;58:e29-e38.

12. de la Rosette J, Collins E, Bachmann A, et al. Historical aspects of laser therapy for benign prostatic hyperplasia. European Urology Supplements 2008;7:361-92.

13. Malek RS, Woo H. Course presented at the American Urological Association Annual Meeting; May 21, 2008; Orlando, FL.

14. Geavlete P. Is classical transurethral resection of the prostate, the gold standard endoscopic treatment for benign prostatic hyperplasia, in real danger of being replaced? Eur Urol 2010;58:356-8; discussion 358-9.

Correspondence: Dr. Edward Woods, The Scarborough Hospital, 3050 Lawrence Ave. E., Scarborough, 0N MIP 2V5; efawoods@rogers.com 